\title{
Prevalence and influencing factors of co-morbid depression in patients with type 2 diabetes mellitus: a General Hospital based study
}

Weijun Zhang ${ }^{1 \dagger}$, Huiwen $\mathrm{Xu}^{2 \dagger}$, Shuliang Zhao ${ }^{3}$, Shinan Yinn ${ }^{4}$, Xiaohua Wang ${ }^{1}$, Jing Guo ${ }^{5}$, Shengfa Zhang ${ }^{1}$, Huixuan Zhou', Fugang Wang ${ }^{1}$, Linni Gu', Lei Zhu', Haibo Yu', Zhiyong Qu ${ }^{1 *}$ and Donghua Tian ${ }^{1 *}$

\begin{abstract}
Background: Depression and diabetes have been recognized as major public health issues in China, however, no studies to date examined the factors associated with the development of depression in patients with diabetes in China. This study aimed to estimate the prevalence of co-morbid depression among adults with type 2 diabetes mellitus (DM) and to examine the influence factors of co-morbid depression in a group of patients with type 2 DM.

Methods: The study was conducted from March I to May 31, 2012, in the Department of Endocrinology of the First Affiliated Hospital of the General Hospital of the People's Liberation Army (PLA). A systematic random sample of 412 type 2 DM patients aged over 18 years was selected. A structured questionnaire was used for collecting the information about socio-demographic data, lifestyle factors and clinical characteristics. Depression and social support was evaluated by using the Chinese version of Beck Depression Inventory (BDI) and Social Support Rate Scale (SSRS), respectively. Weights and heights were measured. Hemoglobin A1c (HbA1c) was abstracted from each patient directly after the interview.

Results: Of the total sample, 142 patients had depression according to the BDI scores (BDI scores $\geq 14$ ), the prevalence of co-morbid depression in this study population was $5.7 \%$ (142/2500). Of which, 56 had major depression (BDI $\geq 21$ ), and 86 had moderate depression (BDI $\geq 14 \& \mathrm{BDI}<21)$. Logistic regression analysis indicated that a high HbA1c level, a high BMl, low quality health insurance, and being single, were significantly associated with the development of depression. However, a family history of diabetes and a high social support level are likely protective factors.

Conclusions: The prevalence of co-morbid depression was $5.7 \%$ among Chinese subjects with type 2 DM in this study. High HbA1c level, high BMI score, being single, low social support level, and low quality health insurance were associated with the presence of depression. These findings support a recommendation for routine screening and management in China for depression in patients with diabetes, especially for those in primary care, to reduce the number of the depressed or the misrecognized depressed diabetic patients.
\end{abstract}

Keywords: Type 2 diabetes mellitus, Depression, Prevalence, Risk factors

\footnotetext{
*Correspondence: qzy@bnu.edu.cn; tian65216@hotmail.com

${ }^{\dagger}$ Equal contributors

'School of Social Development and Public Policy, China Institute of Health, Beijing Normal University, 19, Xinjiekou Wai Street, Beijing 100875, China Full list of author information is available at the end of the article
} 


\section{Introduction}

Diabetes was one of the most important public health problems in China, and there were 113.9 million patients with diabetes and 493.4 million patients with prediabetes among Chinese adults in 2010 [1]. There was also evidence that confirms the adverse economic impacts of co-morbid diabetes and depression [2]. The direct medical costs of type $2 \mathrm{DM}$ and its complications were projected to be 47.2 billion USD in 2030 [3]. Meanwhile, the total estimated cost of depression in China was 6264 million USD at 2002 prices [4]. Previous studies suggested that the prevalence of depressive disorders and its' risk factors may differ between countries and within countries, and across various ethnicities $[5,6]$. It may be related to the differences in either the presentation of symptoms or a lack of cultural appropriateness of western methods of identifying depression [7].

Evidence suggested that diabetes and depression could mutually exacerbate, with each condition acting as a risk factor in the development of the other [8-10]. Songar et al. used a Beck's Depression Inventory score of 14 as cut-off and studied 60 diabetic patients and 30 healthy controls, and found a prevalence of $43.3 \%$ and $3.3 \%$ respectively [11]. In another study, conducted by Peyrot and Rubin, a prevalence of $41.3 \%$ was found among 634 diabetic patients, by using CES-D 16 as cut-off [12]. Pouwer et al. presented a prevalence of $32 \%$ from a random sample of 772 mixed cases of diabetes for study, by using the composite international diagnostic interview and CES-D (cut-off 16) [13]. Raval et al. reported a prevalence of $41 \%$ in North India by using the Patient Health Questionnaire (PHQ)-9 scale [14], while Poongathai et al. reported only $23.4 \%$ from the South of India, by using the PHQ-12 [15]. In 2014, Singh H et al. found a CES-D defined depression prevalence of $42.2 \%$ in diabetes patients in india, which is 10 times higher than controls (4.39\%) [16]. In a meta-analysis of 10 randomly controlled trials on type 2 diabetes mellitus (DM) only, a significantly higher prevalence of depression was found in people with diabetes compared with those without (17.6 vs. $9.8 \%, \mathrm{OR}=1.6$, $95 \%$ CI 1.2-2.0) [17]. A recent systematic review indicated that individuals with previously diagnosed diabetes have an increased risk of depression compared to those with impaired glucose metabolism or undiagnosed diabetes (OR 1.69, 95 \% CI 1.37-2.08) [18]. In addition, other studies indicated that type $2 \mathrm{DM}$ was a risk factor for developing depression $[19,20]$, the incidence of depression was 1.8-times higher in the diabetic group than in nondiabetic subjects over a median follow-up of 6.5 years [21].

Meanwhile, the prevalence of depression always varies internationally among different populations [22]. The higher depression prevalence was found in African Americans with diabetes than in their counterparts of white northern European ancestry [23, 24]. Even higher levels of co-morbid diabetes and depression were also shown in the US Latino population [25-28], Native Americans [29], and Palestine [30]. Overall, it is now generally agreed that the prevalence of depression increased in people with diabetes, although the study, on the Pima Indians in Arizona, found no significant differences in depressive symptoms between those with and without diabetes [31]. Extensive researches had examined the risk factors of depression in patients with type $2 \mathrm{DM}$, the results varied widely across studies [22]. Depression risk factors that are specific to diabetes, included co-morbidity of diabetes-related complications [32], macro-vascular disease (stroke, peripheral artery disease) [33], micro-vascular disease including retinopathy [34], neuropathy and nephropathy [35], longer duration of diabetes [36, 37], more demanding regimens [38], negative life events [39], low levels of daily activities $[40,41]$, physical activity [42], perceived burden of diabetes [43], diabetes diet, increased cholesterol and difficulty in daily living [33], being a female, and being widowed or divorced [44]. Besides, the depression symptoms was also significantly associated with poorer glycemic control [45, 44, 46, 39], the level of HbA1c [45], high fasting insulin values, 2 -h glucose concentrations and insulin resistance [47]. However, several studies showed that the relationship between depression and glycemic control/impaired fasting glucose was uncertain [48] or insignificantly [49-51]. Another 5-year follow-up study showed that previous depression history, baseline diabetes symptoms, and having had cardiovascular procedures significantly predicted major depressive disorder [34]. The course of depression in patients with diabetes is chronic and severe [52], and has significant effects on the outcome of their medical illness [53], including lower quality of life [54], poorer diabetes self-care [55], and an increased risk of developing diabetes-related complications [32]. Just because of this, the International Diabetes Federation (IDF) and National Institute for Health and Clinical Excellence (NICE) recommended that all patients with diabetes should undergo a regular screening for depression $[56,57]$.

To date, no studies have examined the factors associated with depression in patients with diabetes in China. This study aims to investigate the prevalence of depression and explore the influence factors associated with depression in a group of patients with type $2 \mathrm{DM}$.

\section{Methods}

Participants

The study was conducted from March 1 to May 31, 2012, in the Department of Endocrinology of the First Affiliated Hospital of the General Hospital of the People's Liberation Army (PLA), which is one of the best medical centers in China. All of the patients above 
18 years old who were diagnosed with type $2 \mathrm{DM}$ according to the diagnostic criteria of the 10th revision of the International Classification of Diseases (ICD-10) [58], were selected from their medical records. The excluded patients were those having a history of psychiatric illness and those taking anti-depressant treatment and/or using psychotropic drugs, considering that antidepressants or psychotropic drugs may influence the outcome of BDI test. Eventually, there were 12 patients excluded from this study, including 3 patients having a history of psychiatric illness other than depression and 9 patients taking anti-depressant treatment, according to the medical records. 450 subjects were recruited by circular systematic random sampling into this study from 2500 patients. Specifically, the number of 135 was selected as the random starting point, and 6 was taken as the sampling interval. All of the patients were approached at the hospital by their attending diabetologist or diabetes nurse. Five diabetologists and 10 nurses were in charge of completing a structured questionnaire, including demographic information, BDI-21 test, and Social Support Rate Scale (SSRS), measuring weight and heights, and collecting the blood sample of subjects, in a hospital waiting room. The whole process took about 20-30 min per subject. An instruction and scoring manual was supplied to each diabetologist and specialized diabetes nurse in this study. The study protocol was approved by the School of Social Development and Public Policy (SSDPP) ethics committee of Beijing Normal University (BNU) and the research oversight committee of the General Hospital of PLA. The patients were provided written informed consents before the interview.

\section{Measurements}

\section{Demographic information}

The eligible subjects were interviewed using a structured questionnaire. The demographic and socioeconomic factors including age, gender, education level, marriage status, and lifestyle factors (e.g., exercise times per week) were collected.

\section{Depression}

The depressive symptoms were assessed with the Chinese version of the self-administered 21-item Beck Depression Inventory (BDI) [59], and a cut-off value $\geq 14$ was used to define the cases with symptoms of depression in the Chinese population. Cronbach's $\alpha$ of the BDI in this study was 0.88 .

\section{Social support}

Social support was evaluated by using the 14-item social support rate scale (SSRS), which measures objective support, subjective support, and useless support; it was developed by Xiao Shuiyuan in 1986 and validated in a previous study [60]. Cronbach's alpha of the SSRS in this sample was 0.74 , the maximum scores were 50 and the minimum scores were 20 , respectively.

\section{Clinical characteristics}

Glycated Haemoglobin (HbA1c), which is used to measure blood glucose control over several months and provides an estimate of how well diabetes has been controlled over the last 2 or 3 months, was abstracted from each patient directly after the interview. HbA1c determination for all samples was done in the same laboratory by the same technician, who was blind to the diagnosis results of the patients, and applying the same technique. Weight and heights were also measured to calculate the Body Mass Index (BMI). Other clinical characteristics including disease duration, diabetes family history, and diabetic complications (hypertension, cardiac disease, diabetic nephropathy, diabetic retinopathy, and diabetic peripheral angiopathy) were obtained from the standard medical records of the patients under the permission of charge doctors.

\section{Statistical analysis}

The descriptive statistics were used in accordance with the level of the variable measurements. The odds ratio (OR) and its $95 \%$ confidence intervals (CIs) were estimated. The statistical significance of associations was evaluated using the chi-square test, and the $t$ test was performed as appropriate. The level of statistical significance was fixed at 0.05 for the bi-marginal null hypothesis. Multivariate logistic regression analysis were applied to explore the factors associated with depression symptoms. The depression scores $(\geq 14$ versus $<14)$ were used as the dependent variable and the independent variables including the demographic factors, clinical factors, and behaviour factors were introduced into the multivariate logistic regression model, stepwise. All the data were analysed by using SPSS 17.0 (SPSS Inc., Chicago, IL, USA), and $p$ value of $<0.05$ was considered statistically significant.

\section{Results}

\section{Demographic characteristics}

412 patients participated in this study successfully, for a response rate of $91.6 \%$. The other 38 patients, including 18 males, explicitly declined participation in the screening when they were approached by a nurse in the waiting room. These 38 patients did not differ in the demographic variables and the part clinical variables compared with the respondents (Additional file 1). The average age of the sample was 59.77 years (SD 12.48), with a range of 25 to 89 years; $53.6 \%$ of the sample were over 60 , and females comprised $49.8 \%$ of the sample. For all the respondents, $70.1 \%$ were married or living 
with a partner, and $29.9 \%$ were single (including unmarried, divorced and widowed). Of the total sample, $13.3 \%$ had a primary education ( $\leq 6$ years), $39.5 \%$ had completed junior middle school/high school (6-12 years), and $47.1 \%$ had a junior college or more advanced education. Regarding employment, a high percentage of the subjects was retired (62.1\%), followed by being employed (33.5 \%) and being unemployed (4.4\%) (Table 1).

\section{Clinical characteristics and frequency of depression}

Of the total sample, the average duration of diabetes was 8.93 years (SD 6.51), ranging from 1-36 years. Specifically, the average duration of diabetes for the patients with depression symptoms was longer than that without depression symptoms $(10.32 \pm 7.52$ vs $8.20 \pm 5.79, t=-3.17$; $P=0.002$ ). In addition, $83.3 \%$ of the sample had diabetes complications, and the most frequently diagnosed complications were hypertension (88.9 \%), abnormal blood lipids (70.3\%), cardiovascular disease (28.6\%), and diabetic peripheral neuropathy $(25.4 \%)$. The other complications rates included the following: diabetic retinopathy (20.7 \%), cerebrovascular disease (19.0\%), lower limb angiopathy (14.6\%), renal diseases (11.4\%), and other complications (8.2\%).

One hundred and forty two patients (34.5\%) experienced symptoms of depression $(\mathrm{BDI} \geq 14)$, and the prevalence of co-morbid depression was $5.7 \%$ in this study population; 56 patients had major depression $(\mathrm{BDI} \geq 21)$, and 86 patients had moderate depression (BDI $\geq 14 \& B D I<21)$. The patients with symptoms of depression had lower levels of social support $(t=12.60$; $P<0.001)$, and presented poorer glycemic control $\left(\chi^{2}=\right.$ 9.72; $P=0.002)$, a longer duration of diabetes $(\mathrm{t}=-3.17$; $P=0.002)$, and greater number of complications $(\mathrm{t}=-4.98$; $P=0.00$ ) as well as had fewer hours of sleep per day $(\mathrm{t}=4.38 ; P<0.001)$ and fewer exercise sessions per week $(\mathrm{t}=3.35 ; P<0.001)$, compared with the patients without depression (Table 1). The patients with a family history of diabetes presented a lower prevalence of depression symptoms $\left(24.2 \%\right.$ vs $43.2 \%, \chi^{2}=16.42 ; P<$ 0.001 ), compared to the patients without a family history of diabetes in this sample (Table 1 ).

\section{Risk and protective factors associated with depression}

In this study, no significant differences were observed among the patients in different age group diabetes (Table 2). Regarding marital status, being single was a significant risk factor (OR 2.51; 95 \% CI: 1.29-4.90; $P=$ 0.007) compared with being married. The patients covered by Urban Employees Basic Medical Insurance (UEMI) were more likely to suffer from depression symptoms (OR 2.38; $95 \%$ CI: $1.12-5.04 ; P=0.024$ ) compared with the patients covered by the Government
Employee Insurance Scheme (GIS). Consistent with previous findings, social support was also identified as a protective factor (OR 0.76; $95 \%$ CI: $0.69-0.83 ; P<0.0001$ ) (Table 2).

With regard to the clinical characteristics, two risk factors for depression symptoms were identified, including a higher glycated hemoglobin level (HbA1c $\geq 7.00 \%$, OR 1.89; $95 \%$ CI: $1.10-3.53 ; P=0.045)$, and a higher bodymass index (BMI $\geq 25 \mathrm{~kg} / \mathrm{m}^{2}$; OR 1.12; $95 \%$ CI: 1.02-1.24; $P=0.024)$. A family history of diabetes was also identified as a protective factor (OR 0.49; $95 \%$ CI: $0.26-0.90 ; P=$ 0.022 ) in this study.

\section{Discussion}

Depressive symptoms impede diabetes care tasks and negatively influence health status [61, 62]; furthermore, these depression symptoms not only can't be identified by the patients, but also can't be recognized by care providers [61], hence, leading to under-treatment [63]. In this study, we documented that $5.7 \%$ of a study population of type $2 \mathrm{DM}$ patients had symptoms of depression. The prevalence was lower than that reported in India (23.4 \% and above) [11, 14-16] and in Baltimore of USA (41.3\%) [12]. Increased risk of depression in patients with diabetes may be attributed to lifestyle and health behaviors, the previous studies suggested the following important factors are related to depression in patients with diabetes: the occurrence of chronic or acute complications, persistent poor glycemic control and the need for insulin therapy $[46,64,48]$. In this study, we found that a higher HbA1c level was a risk factor for the presence of depression symptoms, rather than the number of diabetes complications. Another two studies have also suggested that depression was strongly associated with poor glycemic control and the number of co-morbid conditions $[46,64]$. There was a different result from another study conducted by Pouwer F et al [65], which showed that the prevalence of depression increased in patients with type $2 \mathrm{DM}$ and co-morbid chronic diseases, but not in patients with type $2 \mathrm{DM}$ only. In addition, functional limitations that often accompany co-morbid chronic disease could play an essential role in the development of depression in type 2 diabetes [65]. Similarly, a recent study suggested that micro- and macro-vascular diabetic complications were associated with depression [66]. Some researchers noted that this may be resulted from the differences in either the presentation of symptoms or a lack of cultural appropriateness of western methods of identifying depression [22, 17]. Lloyd $C E$ etal found that the variation in symptoms and ways to describe depressive symptomatology can be seen as culturally influenced [7]. However, the mechanism for these differences still remains unclear, and should be further examined in the future. For example, 
Table 1 Co-morbid depression (BDI score $\geq 14$ ) and demographic, clinical, and behavior characteristics by depression groups

\begin{tabular}{|c|c|c|c|c|}
\hline Variables & Total sample (n) & No depression n(\%) & Depression n(\%) & Significance \\
\hline$\overline{n(\%)}$ & 412 & $270(65.53)$ & $142(34.47)$ & \\
\hline \multicolumn{5}{|l|}{ Demographic factors } \\
\hline Men & $207(50.24)$ & 134(49.63) & $73(51.41)$ & \multirow[t]{2}{*}{$\left(x^{2}=0.12 ; P=0.73\right)$} \\
\hline Female & 205 (49.76) & 136(66.3) & $69(33.7)$ & \\
\hline \multicolumn{5}{|l|}{ Age (years) } \\
\hline$<40$ & $26(6.31)$ & $9(3.33)$ & $17(11.97)$ & \multirow[t]{3}{*}{$\left(X^{2}=21.51 ; P=0.00\right)$} \\
\hline $40-59$ & $165(40.05)$ & $126(46.67)$ & $39(27.46)$ & \\
\hline$\geq 60$ & $221(53.64)$ & $135(50.00)$ & $86(60.56)$ & \\
\hline High school or less & $218(52.91)$ & 133(49.26) & $85(59.86)$ & $\left(x^{2}=4.20 ; P=0.04\right)$ \\
\hline Being ingle & $123(29.85)$ & $48(17.78)$ & $75(52.82)$ & $\left(X^{2}=54.55 ; P=0.00\right)$ \\
\hline \multicolumn{5}{|l|}{ Employment status } \\
\hline Employed & 138(33.50) & $94(34.81)$ & 44(30.99) & \multirow[t]{3}{*}{$\left(x^{2}=6.09 ; P=0.048\right)$} \\
\hline Unemployed & 18(4.37) & $7(2.59)$ & $11(7.75)$ & \\
\hline Retired & $256(62.14)$ & $169(62.59)$ & $87(61.27)$ & \\
\hline \multicolumn{5}{|l|}{ Insurance } \\
\hline GIS & $130(31.55)$ & $99(36.67)$ & $31(21.83)$ & \multirow[t]{6}{*}{$\left(X^{2}=22.88 ; P=0.00\right)$} \\
\hline UEMI & 112(27.18) & 68(25.19) & 44(30.99) & \\
\hline URMI & 102(24.76) & $60(22.22)$ & $42(29.58)$ & \\
\hline NCMS & 17(4.13) & 16(5.93) & $1(0.70)$ & \\
\hline Other insurance & 19(4.61) & $7(2.59)$ & $12(8.45)$ & \\
\hline None insurance & $32(7.77)$ & $20(7.41)$ & $12(8.45)$ & \\
\hline Social support & $31.35 \pm 5.50$ & $33.45 \pm 4.53$ & $27.35 \pm 4.94$ & $(\mathrm{t}=12.60 ; P=0.00)$ \\
\hline \multicolumn{5}{|l|}{ Clinical factors } \\
\hline \multicolumn{5}{|l|}{ HbA1c level } \\
\hline$<7.00 \%$ & $209(50.73)$ & $152(56.30)$ & $57(40.14)$ & \multirow[t]{2}{*}{$\left(X^{2}=9.72 ; P=0.002\right)$} \\
\hline$\geq 7.00 \%$ & 203(49.27) & 118(43.70) & $85(59.86)$ & \\
\hline \multicolumn{5}{|l|}{$\mathrm{BMI}\left(\mathrm{kg} / \mathrm{m}^{2}\right)$} \\
\hline$<25$ & 215(52.18) & $142(52.59)$ & 73(51.41) & \multirow[t]{2}{*}{$\left(X^{2}=0.05 ; P=0.0819\right.$} \\
\hline$\geq 25$ & 197(47.82) & $128(47.41)$ & $69(48.59)$ & \\
\hline History of diabetes & 190(46.12) & $144(53.33)$ & $46(32.39)$ & $\left(x^{2}=16.42 ; P=0.00\right)$ \\
\hline Duration of diabetes in years & $8.93 \pm 6.51$ & $8.20 \pm 5.79$ & $10.32 \pm 7.52$ & $(\mathrm{t}=-3.17 ; P=0.002)$ \\
\hline Diabetes complications & $2.39 \pm 1.90$ & $2.06 \pm 1.58$ & $3.01 \pm 2.28$ & $(\mathrm{t}=-4.98 ; P=0.00)$ \\
\hline Oral agents & $227(55.10)$ & $148(55.64)$ & 79(54.11) & $\left(X^{2}=0.137 ; P=0.76\right)$ \\
\hline Insulin & 185(44.90) & 118(44.36) & $67(45.89)$ & \\
\hline \multicolumn{5}{|l|}{ Behavior factors } \\
\hline Smoking currently & $112(27.18)$ & $80(29.63)$ & $32(22.54)$ & $\left(X^{2}=2.37 ; P=0.12\right)$ \\
\hline Drinking currently & 198(48.06) & $143(52.96)$ & $55(38.73)$ & $\left(X^{2}=7.55 ; P=0.006\right)$ \\
\hline Excise times per week & $1.67 \pm 2.78$ & $2.00 \pm 2.79$ & $1.04 \pm 2.67$ & $(\mathrm{t}=3.35 ; P=0.00)$ \\
\hline Sleeping hours per day & $5.95 \pm 2.82$ & $6.38 \pm 1.22$ & $5.13 \pm 4.39$ & $(\mathrm{t}=4.38 ; P=0.00)$ \\
\hline
\end{tabular}

it is important to understand the local term(s) and the culturally distinctive understandings of the causes of depression, the effects of particular health problems, and help-seeking in the community if identification and treatment of co-morbid diabetes and depression is to be improved [22].

In addition, a higher BMI $\left(\geq 25 \mathrm{~kg} / \mathrm{m}^{2}\right)$ was also identified as a risk factor for depression symptoms in this 
Table 2 Multivariate logistic regression model predicting co-morbid depression (BDI score $\geq 14$ ) by demographic, clinical, and behavior factors $(n=412)$

\begin{tabular}{|c|c|}
\hline Variables & OR $(95 \%$ Cl) \\
\hline \multicolumn{2}{|l|}{ Demographic factors } \\
\hline Men & $1.13(0.57,2.24)$ \\
\hline \multicolumn{2}{|l|}{ Age } \\
\hline $40-59$ years vs. $<40$ years & $0.29(0.09,0.97)$ \\
\hline$\geq 60$ years vs. $<40$ years & $0.58(0.15,2.27)$ \\
\hline High school or less & $0.94(0.45,1.80)$ \\
\hline Being single & $2.51(1.29,4.90)$ \\
\hline \multicolumn{2}{|l|}{ Employment status } \\
\hline Unemployed vs. employed & $4.39(0.89,21.77)$ \\
\hline Retired vs. employed & $0.74(0.31,1.76)$ \\
\hline \multicolumn{2}{|l|}{ Insurance } \\
\hline UEMI vs. GIS & $2.38(1.12,5.04)$ \\
\hline URMI vs. GIS & $0.95(0.40,2.27)$ \\
\hline NCMS vs. GIS & $0.18(0.19,1.82)$ \\
\hline Other insurance vs. GIS & $1.64(0.38,7.06)$ \\
\hline None insurance vs. GIS & $0.77(0.22,2.65)$ \\
\hline Social support & $0.76(0.69,0.83)$ \\
\hline \multicolumn{2}{|l|}{ Clinical factors } \\
\hline $\mathrm{HbA} 1 \mathrm{c} \geq 7.00 \%$ & $1.89(1.10,3.53)$ \\
\hline $\mathrm{BMI} \geq 25 \mathrm{~kg} / \mathrm{m}^{2}$ & $1.12(1.02,1.24)$ \\
\hline History of diabtes & $0.49(0.26,0.90)$ \\
\hline Duration of diabetes & $1.11(0.72,1.72)$ \\
\hline Diabetes complications & $1.12(0.94,1.34)$ \\
\hline Oral agents & $1.05(0.41,2.73)$ \\
\hline Insulin & $1.93(0.99,3.82)$ \\
\hline \multicolumn{2}{|l|}{ Behavior factors } \\
\hline Smoking currently & $1.02(0.45,2.32)$ \\
\hline Drinking currently & $0.65(0.30,1.42)$ \\
\hline Excise times per week & $0.92(0.46,1.86)$ \\
\hline Sleeping hours per day & $0.82(0.67,1.00)$ \\
\hline
\end{tabular}

study. It was consistent with a previous study [67] which indicated that the BMI contributed to depression indirectly via diabetes-related medical symptoms. Previous study showed that insulin therapy has a significant association with depression among adult patients with diabetes [68], however, insulin therapy wasn't associated with the depression symptoms in this study, this may be related to the characteristics and the size of this sample.

It's interesting that a family history of diabetes was identified as a protective factor against symptoms of depression in patients with diabetes in this study. A previous study suggested that an increase in knowledge concerning diabetes care could relieve symptoms of anxiety and depression [69]. A positive family setting provides an opportunity for a patient to obtain personal experience in chronic disease management and consequently manage his/her own disease more effectively [70]. Another protective factor against the presence of depression symptoms was the high social support level in this study. Previous study also confirmed this result, which suggested that if social support level can be strengthened in patients with type $2 \mathrm{DM}$, psychological factors can be improved [71]. A mediation analysis indicated that the effect of social support on diabetes-related medical symptoms was fully accounted for by social support's adverse effect on depression [72]. A communitybased study on the patients with type $2 \mathrm{DM}$, in China, showed that high salary and more subjective social support could improve the quality of life in diabetic patients with depressive symptoms [73].

Being single, including being unmarried, widowed, and divorced, was also identified as a risk factor for symptoms of depression, which coincides with the results as reported by José Francisco [46] and M. M. Collins [48]. Being different from the previous studies, which showed that women with or without diabetes experience a higher prevalence of depression than men [62, 64, 48, 74], no significant difference was observed between males and females in this study. The reasons for these differences are unclear and should be further examined in the future, which is most likely connected with the variance of research methods and population characteristics.

In addition, we found that the patients covered by UEMI were more likely to suffer from symptoms of depression compared with the patients covered by GIS. In China, the patients covered by GIS have the highest reimbursement rates, so they had a lighter burden of medical care and less disease-related mental stress than the patients, covered by UEMI, who personally incur high medical expenses.

Type $2 \mathrm{DM}$ is a crucial public health issue in China, with massive medical, social, and economic effects; few studies focus on depression in patients with diabetes. The results of this study should be further confirmed in the future, and should be investigated in different populations, to present a more comprehensive representation of the magnitude of this problem. The incidence of depression in patients with type $2 \mathrm{DM}$ mellitus should be paid more attention.

\section{Limitations}

Our study may be the first to be conducted in China to investigate the prevalence and influencing factors of undiagnosed depression depression in patients with type 2 diabetes mellitus. Systematic random sampling technique, Beck Depression Inventory (BDI), and Social Support Rate Scale (SSRS) were also used in our study. However, our study has a few limitations. First, the samples were 
recruited from a general hospital and could not represent all of the patients in China. Second, the excluding cases of diagnosed depression in this study also had influence on the prevalence of depression symptoms among the patients with type 2 DM. Third, this study is cross-sectional where causal relationship between diabetes and depression cannot be established. Variables identified as significantly associated with depression may precede depression, but in some cases, these variables could also occur as a result of depression; thus, high BDI scores among patients with diabetes must be interpreted with caution. Longitudinal prospective studies are needed to shed more light on the potential relationship between depression and diabetes mellitus in the future.

\section{Conclusions}

The prevalence of co-morbid depression was $5.7 \%$ among Chinese subjects with type $2 \mathrm{DM}$ in this study. High HbA1c level, high BMI score, being single, and low quality health insurance were associated with the presence of depression. These findings support a recommendation for routine screening in China for depression in patients with diabetes, especially for those in primary care, to reduce the number of the depressed or the misrecognized depressed diabetic patients and consequently offer them a better quality of life.

\section{Additional file}

Additional file 1: The characteristic of non-responders in this study.

\section{Competing interests}

The authors declare that they have no competing interests.

\section{Authors' contributions}

DT, ZQ and SY gave us the idea of this study. WZ, HX and SZ participated in the design and conducted the research as well as drafted the manuscript. XW and JG helped revise the manuscript. SY gave us a lot of help during the process of this study, SZ, HZ, FW, LG, HY, and LZ provided the data analysis help. All the authors read and approved the final manuscript.

\section{Acknowledgments}

We thank Beijing Normal University for giving financial support. We also thank the hospital officials and the data collectors for providing the support for this study, and all the respondents for participating our study.

\section{Funding sources}

This study was supported by the Fundamental Research Funds for the Central Universities (No: SKZZX2013053 in Beijing Normal University).

\footnotetext{
Author details

${ }^{1}$ School of Social Development and Public Policy, China Institute of Health, Beijing Normal University, 19, Xinjiekou Wai Street, Beijing 100875, China. ${ }^{2}$ Department of Public Health Sciences, University of Rochester School of Medicine \& Dentistry, Rochester, NY 14642, USA. ${ }^{3}$ School of Public Administration, Yunnan University of Finance and Economics, Kunming 650221, China. ${ }^{4}$ Department of Endocrinology, First Affiliated Hospital of the General Hospital of the People's Liberation Army (PLA), Beijing 100853, China. ${ }^{5}$ Department of Sociology, Huazhong University of Science and Technology, 1037 Luoyu Road, Wuhan 430074, China. ${ }^{6}$ School of Government, Beijing Normal University, 19, Xinjiekou Wai Street, Beijing 100875, China.
}

Received: 16 March 2015 Accepted: 17 June 2015

Published online: 30 June 2015

\section{References}

1. Xu Y, Wang L, He J, Bi Y, Li M, Wang T, et al. Prevalence and control of diabetes in Chinese adults. JAMA. 2013;310(9):948-59. doi:10.1001/ jama.2013.168118.

2. Molosankwe I, Patel A, José Gagliardino J, Knapp M, McDaid D. Economic aspects of the association between diabetes and depression: A systematic review. J Affect Disord. 2012;142(Supplement(0)):S42-55. http://dx.doi.org/ 10.1016/S0165-0327(12)70008-3.

3. Wang W, McGreevey WP, Fu C, Zhan S, Luan R, Chen W, et al. Type 2 diabetes mellitus in China: a preventable economic burden. Am J Manag Care. 2009;15(9):593-601.

4. Hu TW, He Y, Zhang M, Chen N. Economic costs of depression in China. Soc Psychiatry Psychiatr Epidemiol. 2007;42(2):110-6. doi:10.1007/s00127-006-0151-2.

5. Chaudhry I, Neelam K, Duddu V, Husain N. Ethnicity and psychopharmacology. J Psychopharmacol. 2008;22(6):673-80. doi:10.1177/ 0269881107082105.

6. Bhugra D, Bhui K. Ethnic and cultural factors in psychopharmacology. Adv Psychiatr Treat. 1999;5:89-95.

7. Lloyd CE, Roy T, Begum S, Mughal S, Barnett AH. Measuring psychological well-being in South Asians with diabetes; a qualitative investigation of the PHQ-9 and the WHO-5 as potential screening tools for measuring symptoms of depression. Diabet Med. 2012;29(1):140-7. doi:10.1111/j.1464-5491.2011.03481.x.

8. Nouwen A, Winkley K, Twisk J, Lloyd CE, Peyrot M, Ismail K, et al. Type 2 diabetes mellitus as a risk factor for the onset of depression: a systematic review and meta-analysis. Diabetologia. 2010;53(12):2480-6. doi:10.1007/ s00125-010-1874-X.

9. El-Hechmi S, Zgueb Y, Jomli R, Ouanes S, Nacef F, Turki Z. 2859 Depression and diabetes comorbidity: prevalence and clinical features. Eur Psychiatry. 2013;28(Supplement 1(0)):1. http://dx.doi.org/10.1016/S09249338(13)77440-6.

10. Kokoszka A, Pouwer F, Jodko A, Radzio R, Mućko P, Bieńkowska J, et al. Serious diabetes-specific emotional problems in patients with type 2 diabetes who have different levels of comorbid depression: A Polish study from the European Depression in Diabetes (EDID) Research Consortium. Eur Psychiatry. 2009;24(7):425-30. http://dx.doi.org/10.1016/j.eurpsy.2009.04.002.

11. Songar A, Kocabaşoğlu N, Balcioğlu I, Karaca E, Kocabaşoğlu C, Hacıosman $\mathrm{M}$, et al. The relationship between diabetics' metabolic control levels and psychiatric symptomatology. Integr Psychiatry. 1993;9(1):34-40.

12. Peyrot M, Rubin RR. Levels and risks of depression and anxiety symptomatology among diabetic adults. Diabetes Care. 1997;20(4):585-90.

13. Pouwer F, Kupper N, Adriaanse MC. Does emotional stress cause type 2 diabetes mellitus? A review from the European Depression in Diabetes (EDID) Research Consortium. Discov Med. 2010;9(45):112-8.

14. Raval A, Dhanaraj E, Bhansali A, Grover S, Tiwari P. Prevalence \& determinants of depression in type 2 diabetes patients in a tertiary care centre. Indian J Med Res. 2010;132:195-200.

15. Poongothai S, Anjana RM, Pradeepa R, Ganesan A, Unnikrishnan R, Rema M, et al. Association of depression with complications of type 2 diabetes-the Chennai Urban Rural Epidemiology Study (CURES- 102). J Assoc Physicians India. 2011;59:644-8.

16. Singh H, Raju MSVK, Dubey V, Kurrey R, Bansal S, Malik M. A study of sociodemographic clinical and glycemic control factors associated with co-morbid depression in type 2 diabetes mellitus. Ind Psychiatry J. 2014;23(2):134-42.

17. Ali S, Stone MA, Peters JL, Davies MJ, Khunti K. The prevalence of co-morbid depression in adults with Type 2 diabetes: a systematic review and meta-analysis. Diabet Med. 2006;23(11):1165-73. doi:10.1111/j.14645491.2006.01943.x

18. Nouwen A, Nefs G, Caramlau I, Connock M, Winkley K, Lloyd CE, et al. Prevalence of depression in individuals with impaired glucose metabolism or undiagnosed diabetes: a systematic review and meta-analysis of the European Depression in Diabetes (EDID) Research Consortium. Diabetes Care. 2011;34(3):752-62. doi:10.2337/dc10-1414.

19. Hasan SS, Mamun AA, Clavarino AM, Kairuz T. Incidence and risk of depression associated with diabetes in adults: evidence from longitudinal studies. Community Ment Health J. 2015;51(2):204-10. doi:10.1007/s10597014-9744-5. 
20. Rotella F, Mannucci E. Diabetes mellitus as a risk factor for depression. A meta-analysis of longitudinal studies. Diabetes Res Clin Pract. 2013;99(2):98-104. doi:10.1016/j.diabres.2012.11.022.

21. Hsu YM, Su LT, Chang HM, Sung FC, Lyu SY, Chen PC. Diabetes mellitus and risk of subsequent depression: a longitudinal study. Int J Nurs Stud. 2012;49(4):437-44. doi:10.1016/j.jinurstu.2011.09.019.

22. Lloyd CE, Roy T, Nouwen A, Chauhan AM. Epidemiology of depression in diabetes: international and cross-cultural issues. J Affect Disord. 2012;142(Suppl):S22-9. doi:10.1016/S0165-0327(12)70005-8.

23. Gary TL, Crum RM, Cooper-Patrick L, Ford D, Brancati FL. Depressive symptoms and metabolic control in African-Americans with type 2 diabetes. Diabetes Care. 2000;23(1):23-9.

24. Thomas J, Jones G, Scarinci I, Brantley P. A descriptive and comparative study of the prevalence of depressive and anxiety disorders in low-income adults with type 2 diabetes and other chronic illnesses. Diabetes Care 2003;26(8):2311-7

25. Trief PM, Morin PC, Izquierdo R, Teresi J, Eimicke JP, Goland R, et al. Depression and glycemic control in elderly ethnically diverse patients with diabetes: the IDEATel project. Diabetes Care. 2006;29(4):830-5.

26. Egede $L E$, Zheng D. Independent factors associated with major depressive disorder in a national sample of individuals with diabetes. Diabetes Care. 2003;26(1):104-11.

27. Bell RA, Smith SL, Arcury TA, Snively BM, Stafford JM, Quandt SA. Prevalence and correlates of depressive symptoms among rural older African Americans, Native Americans, and whites with diabetes. Diabetes Care. 2005;28(4):823-9.

28. Fisher L, Chesla CA, Mullan JT, Skaff MM, Kanter RA. Contributors to depression in Latino and European-American patients with type 2 diabetes. Diabetes Care. 2001;24(10):1751-7.

29. Singh PK, Looker HC, Hanson RL, Krakoff J, Bennett PH, Knowler WC. Depression, diabetes, and glycemic control in Pima Indians. Diabetes Care. 2004;27(2):618-9.

30. Sweileh WM, Abu-Hadeed HM, Al-Jabi SW, Zyoud SH. Prevalence of depression among people with type 2 diabetes mellitus: a cross sectional study in Palestine. BMC Public Health. 2014;14:163. doi:10.1186/1471-2458-14-163.

31. Sahota PK, Knowler WC, Looker HC. Depression, diabetes, and glycemic control in an American Indian community. J Clin Psychiatry. 2008:69(5):800-9.

32. de Groot M, Anderson R, Freedland KE, Clouse RE, Lustman PJ. Association of depression and diabetes complications: a meta-analysis. Psychosom Med. 2001;63(4):619-30.

33. Bruce DG, Casey G, Davis WA, Starkstein SE, Clarnette RC, Foster JK, et al. Vascular depression in older people with diabetes. Diabetologia. 2006;49(12):2828-36. doi:10.1007/s00125-006-0478-y.

34. Katon W, Russo J, Lin EH, Heckbert SR, Ciechanowski P, Ludman EJ, et al. Depression and diabetes: factors associated with major depression at five-year follow-up. Psychosomatics. 2009;50(6):570-9. doi:10.1176/ appi.psy.50.6.570

35. van Steenbergen-Weijenburg KM, van Puffelen AL, Horn EK, Nuyen J, van Dam PS, van Benthem TB, et al. More co-morbid depression in patients with Type 2 diabetes with multiple complications. An observational study at a specialized outpatient clinic. Diabet Med. 2011;28(1):86-9.

36. Padgett DK. Sociodemographic and disease-related correlates of depressive morbidity among diabetic patients in Zagreb, Croatia. J Nerv Ment Dis. 1993;181(2):123-9.

37. Bruce DG, Davis WA, Davis TM. Longitudinal predictors of reduced mobility and physical disability in patients with type 2 diabetes: the Fremantle Diabetes Study. Diabetes Care. 2005;28(10):2441-7.

38. Surwit RS, van Tilburg MA, Parekh PI, Lane JD, Feinglos MN. Treatment regimen determines the relationship between depression and glycemic control. Diabetes Res Clin Pract. 2005;69(1):78-80. doi:10.1016/ j.diabres.2004.11.002

39. Naranjo DM, Fisher L, Arean PA, Hessler D, Mullan J. Patients with type 2 diabetes at risk for major depressive disorder over time. Ann Fam Med. 2011;9(2):115-20. doi:10.1370/afm.1212.

40. Wikblad KF, Wibell LB, Montin KR. Health and unhealth in chronic disease. Scand J Caring Sci. 1991;5(2):71-7.

41. Pawaskar MD, Anderson RT, Balkrishnan R. Self-reported predictors of depressive symptomatology in an elderly population with type 2 diabetes mellitus: a prospective cohort study. Health Qual Life Outcomes. 2007:5:50. doi:10.1186/1477-7525-5-50.
42. Lysy Z, Da Costa D, Dasgupta K. The association of physical activity and depression in Type 2 diabetes. Diabet Med. 2008;25(10):1133-41. doi:10.1111/j.1464-5491.2008.02545.x.

43. Polonsky WH, Anderson BJ, Lohrer PA, Welch G, Jacobson AM, Aponte JE, et al. Assessment of diabetes-related distress. Diabetes Care. 1995;18(6):754-60.

44. Golden SH, Lazo M, Carnethon M, Bertoni AG, Schreiner PJ, Diez Roux AV, et al. Examining a bidirectional association between depressive symptoms and diabetes. JAMA. 2008;299(23):2751-9. doi:10.1001/jama.299.23.2751.

45. Fisher L, Skaff MM, Mullan JT, Arean P, Glasgow R, Masharani U. A longitudinal study of affective and anxiety disorders, depressive affect and diabetes distress in adults with Type 2 diabetes. Diabet Med. 2008;25(9):1096-101. doi:10.1111/j.1464-5491.2008.02533.x.

46. Tellez-Zenteno JF, Cardiel MH. Risk factors associated with depression in patients with type 2 diabetes mellitus. Arch Med Res. 2002;33(1):53-60.

47. Holt RI, Phillips DI, Jameson KA, Cooper C, Dennison EM, Peveler RC. The relationship between depression and diabetes mellitus: findings from the Hertfordshire Cohort Study. Diabet Med. 2009;26(6):641-8. doi:10.1111/ j.1464-5491.2009.02742.x

48. Collins MM, Corcoran P, Perry IJ. Anxiety and depression symptoms in patients with diabetes. Diabet Med. 2009;26(2):153-61. doi:10.1111/j.14645491.2008.02648.x.

49. Engum A. The role of depression and anxiety in onset of diabetes in a large population-based study. J Psychosom Res. 2007;62(1):31-8. doi:10.1016/ j.jpsychores.2006.07.009.

50. Lin EH, Heckbert SR, Rutter CM, Katon WJ, Ciechanowski P, Ludman EJ, et al. Depression and increased mortality in diabetes: unexpected causes of death. Ann Fam Med. 2009;7(5):414-21. doi:10.1370/afm.998.

51. Knol MJ, Heerdink ER, Egberts AC, Geerlings MI, Gorter KJ, Numans ME, et al. Depressive symptoms in subjects with diagnosed and undiagnosed type 2 diabetes. Psychosom Med. 2007;69(4):300-5. doi:10.1097/ PSY.0b013e31805f48b9.

52. Katon WJ. The comorbidity of diabetes mellitus and depression. Am J Med 2008;121(11 Suppl 2):S8-S15. doi:10.1016/j.amjmed.2008.09.008.

53. Wu SF, Huang YC, Liang SY, Wang TJ, Lee MC, Tung HH. Relationships among depression, anxiety, self-care behaviour and diabetes education difficulties in patients with type-2 diabetes: a cross-sectional questionnaire survey. Int J Nurs Stud. 2011;48(11):1376-83. doi:10.1016/j.jnurstu.2011.04.008.

54. Schram MT, Baan CA, Pouwer F. Depression and quality of life in patients with diabetes: a systematic review from the European depression in diabetes (EDID) research consortium. Curr Diabetes Rev. 2009;5(2):112-9.

55. Gonzalez JS, Peyrot M, McCarl LA, Collins EM, Serpa L, Mimiaga MJ, et al. Depression and diabetes treatment nonadherence: a meta-analysis. Diabetes Care. 2008;31(12):2398-403. doi:10.2337/dc08-1341.

56. International Diabetes Federation. Global guideline for type 2 diabetes. Available from http://www.idf.org/global-guideline-type-2-diabetes-2012, accessed 28 September 20132012.

57. Jones AG, Knight BA, Baker GC, Hattersley AT. Practical implications of choice of test in National Institute for Health and Clinical Excellence (NICE) guidance for the prevention of Type 2 diabetes. Diabet Med. 2013;30(1):126-7. doi:10.1111/dme.12025.

58. Alberti KG, Zimmet PZ. Definition, diagnosis and classification of diabetes mellitus and its complications. Part 1: diagnosis and classification of diabetes mellitus provisional report of a WHO consultation. Diabet Med 1998;15(7):539-53. doi:10.1002/(SICI)1096-9136(199807)15:7<539::AIDDIA668>3.0.CO;2-S

59. Zheng YP, Wei LA, Goa LG, Zhang GC, Wong CG. Applicability of the Chinese Beck Depression Inventory. Compr Psychiatry. 1988;29(5):484-9.

60. Shuiyuan X. Theoretical Background Study and Application of Social Support Rate Scale (in Chinese). J Clin Psychiatry. 1994;02:98-100.

61. Fleer J, Tovote KA, Keers JC, Links TP, Sanderman R, Coyne JC, et al. Screening for depression and diabetes-related distress in a diabetes outpatient clinic. Diabet Med. 2013;30(1):88-94. doi:10.1111/dme.12001.

62. Roy T, Lloyd CE. Epidemiology of depression and diabetes: a systematic review. J Affect Disord. 2012;142(Suppl):S8-S21. doi:10.1016/S01650327(12)70004-6.

63. Li C, Ford ES, Zhao G, Balluz LS, Berry JT, Mokdad AH. Undertreatment of mental health problems in adults with diagnosed diabetes and serious psychological distress: the behavioral risk factor surveillance system, 2007. Diabetes Care. 2010;33(5):1061-4. doi:10.2337/dc09-1515. 
64. Icks A, Kruse J, Dragano N, Broecker-Preuss M, Slomiany U, Mann K, et al. Are symptoms of depression more common in diabetes? Results from the Heinz Nixdorf Recall study. Diabet Med. 2008;25(11):1330-6. doi:10.1111/ j.1464-5491.2008.02585.x.

65. Pouwer F, Beekman AT, Nijpels G, Dekker JM, Snoek FJ, Kostense PJ, et al. Rates and risks for co-morbid depression in patients with Type 2 diabetes mellitus: results from a community-based study. Diabetologia. 2003;46(7):892-8. doi:10.1007/s00125-003-1124-6.

66. Siddiqui S. Depression in type 2 diabetes mellitus - A brief review. Diabetes \& Metabolic Syndrome: Clinical Research \& Reviews. 2013. http://dx.doi.org/ 10.1016/j.dsx.2013.06.010

67. Sacco WP, Wells KJ, Friedman A, Matthew R, Perez S, Vaughan CA.

Adherence, body mass index, and depression in adults with type 2 diabetes: the mediational role of diabetes symptoms and self-efficacy. Health Psychol. 2007;26(6):693-700. doi:10.1037/0278-6133.26.6.693.

68. Al-Amer RM, Sobeh MM, Zayed AA, Al-Domi HA. Depression among adults with diabetes in Jordan: risk factors and relationship to blood sugar control. J Diabetes Complicat. 2011;25(4):247-52. doi:10.1016/j.jdiacomp.2011.03.001.

69. Rubin RR, Peyrot M, Saudek CD. Effect of diabetes education on self-care, metabolic control, and emotional well-being. Diabetes Care. 1989;12(10):673-9.

70. Fan CA, Sattler L, Parkinson C, Thekadeth BG, Singh SP, Perlmuter LC. The effect of family history of diabetes on sleep quality, depression, and anxiety in adult males with diabetes. J Diabetes Mellitus. 2013;3(01):11-4.

71. Wu SF, Young LS, Yeh FC, Jian YM, Cheng KC, Lee MC. Correlations among social support, depression, and anxiety in patients with type-2 diabetes. J Nurs Res. 2013;21(2):129-38. doi:10.1097/jnr.0b013e3182921fe1.

72. Sacco WP, Yanover T. Diabetes and depression: the role of social support and medical symptoms. J Behav Med. 2006;29(6):523-31. doi:10.1007/ s10865-006-9072-5.

73. Liu Y, Maier M, Hao Y, Chen Y, Qin Y, Huo R. Factors related to quality of life for patients with type 2 diabetes with or without depressive symptoms - results from a community-based study in China. J Clin Nurs. 2013;22(1-2):80-8. doi:10.1111/jocn.12010.

74. Lyrakos GN, Papazafiropoulou AK, Batistaki C, Xatziagelaki E, Damigos D, Tinas C, et al. 1412 - Differences in depression anxiety and stress among men and women with diabetes mellitus. Eur Psychiatry. 2013;28(Supplement 1(0)):1. http://dx.doi.org/10.1016/S0924-9338(13)76450-2.

\section{Submit your next manuscript to BioMed Central and take full advantage of:}

- Convenient online submission

- Thorough peer review

- No space constraints or color figure charges

- Immediate publication on acceptance

- Inclusion in PubMed, CAS, Scopus and Google Scholar

- Research which is freely available for redistribution 